\title{
Quality of Life in Oncological Patients with Oropharyngeal Dysphagia: Validity and Reliability of the Dutch Version of the MD Anderson Dysphagia Inventory and the Deglutition Handicap Index
}

\author{
Renée Speyer · Bas J. Heijnen · Laura W. Baijens • \\ Femke H. Vrijenhoef • Elsemieke F. Otters • \\ Nel Roodenburg • Hans C. Bogaardt
}

Received: 25 March 2010/Accepted: 6 January 2011/Published online: 29 January 2011

(C) The Author(s) 2011. This article is published with open access at Springerlink.com

\begin{abstract}
Quality of life is an important outcome measurement in objectifying the current health status or therapy effects in patients with oropharyngeal dysphagia. In this study, the validity and reliability of the Dutch version of the Deglutition Handicap Index (DHI) and the MD Anderson Dysphagia Inventory (MDADI) have been determined for oncological patients with oropharyngeal dysphagia. At Maastricht University Medical Center, 76 consecutive patients were selected and asked to fill in three questionnaires on quality of life related to oropharyngeal
\end{abstract}

\section{R. Speyer}

Department of Speech and Language Pathology,

HAN University of Applied Sciences, Kapittelweg 33,

6525 EN Nijmegen, The Netherlands

\section{R. Speyer}

Department of Trauma Surgery, Leiden University Medical Center, P.O. Box 9600, 2300 RC Leiden, The Netherlands

R. Speyer $(\bowtie) \cdot$ B. J. Heijnen · L. W. Baijens ·

F. H. Vrijenhoef · E. F. Otters

Department of Otorhinolaryngology and Head and Neck

Surgery, Maastricht University Medical Center,

P.O. Box 5800, 6202 AZ Maastricht, The Netherlands

e-mail: r.speyer@online.nl

\section{B. J. Heijnen}

Department of Otorhinolaryngology and Head and Neck

Surgery, Leiden University Medical Center,

P.O. Box 9600, 2300 RC Leiden, The Netherlands

N. Roodenburg

Department of Neurology, Maastricht University Medical

Center, P.O. Box 5800, 6202 AZ Maastricht, The Netherlands

H. C. Bogaardt

Cancer Registration Research and Medical Care, Comprehensive

Cancer Center West, Schuttersveld 2, 2316 ZA Leiden,

The Netherlands dysphagia (the SWAL-QOL, the MDADI, and the DHI) as well as a simple one-item visual analog Dysphagia Severity Scale. None of the quality-of-life questionnaires showed any floor or ceiling effect. The test-retest reliability of the MDADI and the Dysphagia Severity Scale proved to be good. The test-retest reliability of the DHI could not be determined because of insufficient data, but the intraclass correlation coefficients were rather high. The internal consistency proved to be good. However, confirmatory factor analysis could not distinguish the underlying constructs as defined by the subscales per questionnaire. When assessing criterion validity, both the MDADI and the DHI showed satisfactory associations with the SWAL-QOL (reference or gold standard) after having removed the less relevant subscales of the SWAL-QOL. In conclusion, when assessing the validity and reliability of the Dutch version of the DHI or the MDADI, not all psychometric properties have been adequately met. In general, because of difficulties in the interpretation of study results when using questionnaires lacking sufficient psychometric quality, it is recommended that researchers strive to use questionnaires with the most optimal psychometric properties.

Keywords Dysphagia - Deglutition disorders . Quality of life · Validity · Reliability .

Head and neck cancer · Deglutition

Patients with advanced head and neck cancer often suffer from oropharyngeal dysphagia as a result of the disease itself or its treatment [1]. Dysphagia can lead to malnutrition and dehydration as well as an increased risk of aspiration [2]. When objectifying a patient's current health status and the effects of a therapeutic intervention, a quality-of-life instrument is considered an important evaluation tool [3]. 
A few questionnaires on health-related quality of life with respect to oropharyngeal dysphagia can be found in the literature: the SWAL-QOL [4], the MD Anderson Dysphagia Inventory (MDADI) [5], and the Deglutition Handicap Index (DHI) [6]. When a questionnaire is to be used for research, its psychometric characteristics must be well known and of sufficiently high quality, otherwise the study results cannot be interpreted or attributed any clinical relevance. Although the reliability and validity of the SWAL-QOL has been described [4], little is known about the psychometric quality of the MDADI or the DHI. The SWAL-QOL is an elaborate 44-item questionnaire containing 11 subscales. Although the SWAL-QOL is commonly used in research, its application in daily clinical practice is limited since clinicians need a short, easy-tohandle questionnaire for screening. In that light, the validity and reliability of the Dutch version of the DHI and the MDADI for use with oncological patients with oropharyngeal dysphagia was determined in this study.

\section{Methods}

\section{Subjects}

Patients were selected consecutively at the outpatient clinic for dysphagia at the Department of Otorhinolaryngology, Head and Neck Surgery and at the MAASTRO clinic in the Academic Hospital, both part of Maastricht University Medical Center (MUMC). Recruitment took place during visits to the outpatient clinic. A small number of patients were recruited by phone after having studied their medical records. To be included in the sample, a patient must have been diagnosed by a laryngologist as having oropharyngeal dysphagia due to oncological disorders. Furthermore, a patient's general condition must have been stable during repeated measurements. Finally, a patient could not have any cognitive limitations. The selected patients received verbal information about the study and were included in the sample only after giving their informed consent.

In total, 76 patients were included in the study: 57 (75\%) men and $19(25 \%)$ women, ranging in age from 45 to 83 years. The mean age was 64 for men and 61 for women. The status of the oral feeding restrictions was scored using the Functional Oral Intake Scale (FOIS) of Crary et al. [7]. Two subjects were tube dependent while all other subjects were on a totally oral diet. The latter took various forms: a diet of a single consistency $(N=7)$, one of multiple consistencies and requiring special preparation or compensation $(N=30)$, one not needing any special preparation but with some food limitations $(N=28)$, and a normal oral $\operatorname{diet}(N=9)$.

\section{Questionnaires}

This study used four questionnaires: three on quality of life related to oropharyngeal dysphagia, namely, the SWALQOL [4], the MDADI [5], and the DHI [6]; plus a simple one-item visual analog scale, the Dysphagia Severity Scale. Both the MDADI and the DHI were translated into Dutch by three independent researchers; their versions were combined by mutual consensus to form one final translation. The Dysphagia Severity Scale needed no translation, and the SWAL-QOL had already been translated by Bogaardt et al. [8].

The first questionnaire, the SWAL-QOL, is considered the gold standard for determining quality of life in persons with oropharyngeal dysphagia. This 44-item tool exhibits good internal-consistency reliability and short-term reproducibility [4]. It consists of 11 subscales (see Table 1). The minimum and maximum scores per subscale are zero and 100 , indicating an extremely impaired quality of life (0) versus no impairment (100) as experienced by the individual.

The DHI is a 30-item questionnaire on deglutitionrelated aspects of daily life (5-point rating scale: $0-4)$. The questionnaire is subdivided into three domains of ten items: emotional (psychosocial consequences), functional (nutritional and respiratory consequences), and physical (symptoms related to swallowing). The minimum scores range from zero (indicating no handicap) to 120 (indicating maximum handicap) [6].

The MDADI consists of 20 items. Besides a global assessment (a single question), it comprises three subscales: the emotional subscale ( 8 items), the functional subscale (5 items), and the physical subscale (6 items). The global assessment refers to the individual's swallowing difficulty as it affects one's overall daily routine. The emotional, functional, and physical subscales refer to the individual's affective response to the swallowing disorder, the impact of the disorder on daily activities, and the self-perception of the swallowing difficulties, respectively [5]. Using a five-point scale (1-5), the minimum total score is 20 and the maximum 100. In the original version of the MDADI, all but two items were scored such that higher scores indicated higher functioning. In the Dutch translation, it was decided to use a uniform scoring method. Thus, by adjusting the scoring of two items, low scores came to indicate low functioning and high scores high functioning.

The Dysphagia Severity Scale is a self-designed evaluation tool consisting of one visual analog scale, quantifying the severity of the swallowing disorder and the extent of impairment experienced by the patient. A score of 100 (the maximum) indicates normal swallowing abilities, while a score of zero indicates extreme swallowing impairment or inability to swallow. 
Table 1 Descriptive analysis of the MD Anderson Dysphagia Inventory (MDADI), the Deglutition Handicap Index (DHI), the Dysphagia Severity Scale, and the SWAL-QOL
${ }^{a}$ Lower scores indicate more severely impaired quality of life or ability to swallow (MDADI, Dysphagia Severity Scale, SWAL-QOL)

${ }^{\mathrm{b}}$ Higher scores indicate more severely impaired quality of life (DHI)

c According to Chen et al. [5] the range of scores is 0 to 100 , while using a scale of $1-5$. In this study the range of scores has been adjusted

\begin{tabular}{|c|c|c|c|}
\hline Quality-of-life scale & Range of scale & $\begin{array}{l}\text { Median } \\
\left(25^{\prime} ; 75^{\prime} \text { percentiles }\right)\end{array}$ & $N$ \\
\hline \multicolumn{4}{|l|}{ SWAL QOL ${ }^{\mathrm{a}}$} \\
\hline Burden & $0-100$ & $63(6 ; 75)$ & 73 \\
\hline Food selection & $0-100$ & $75(25 ; 88)$ & 71 \\
\hline Eating duration & $0-100$ & $25(0 ; 63)$ & 71 \\
\hline Eating desire & $0-100$ & $75(27 ; 100)$ & 72 \\
\hline Fear & $0-100$ & $88(69 ; 100)$ & 71 \\
\hline Sleep & $0-100$ & $75(44 ; 88)$ & 73 \\
\hline Fatigue & $0-100$ & $58(33 ; 83)$ & 73 \\
\hline Communication & $0-100$ & $63(50 ; 88)$ & 71 \\
\hline Mental health & $0-100$ & $65(30 ; 90)$ & 71 \\
\hline Social functioning & $0-100$ & $65(25 ; 92)$ & 73 \\
\hline Symptoms & $0-100$ & $63(44 ; 77)$ & 73 \\
\hline \multicolumn{4}{|l|}{$\mathrm{DHI}^{\mathrm{b}}$} \\
\hline Total score & $0-120$ & $36(20 ; 46)$ & 42 \\
\hline Emotional subscore & $0-40$ & $10(2 ; 22)$ & 46 \\
\hline Functional subscore & $0-40$ & $12(8 ; 19)$ & 44 \\
\hline Physical Subscore & $0-40$ & $10(6 ; 16)$ & 44 \\
\hline \multicolumn{4}{|l|}{$\mathrm{MDADI}^{\mathrm{a}, \mathrm{c}}$} \\
\hline Total score & $20-100^{2}$ & $66(51 ; 77)$ & 74 \\
\hline Global assessment & $1-5$ & $4(2 ; 4)$ & 76 \\
\hline Emotional subscore & $6-30$ & $20(15 ; 25)$ & 75 \\
\hline Functional Subscore & $5-25$ & $17(13 ; 21)$ & 75 \\
\hline Physical subscore & $8-40$ & $25(19 ; 29)$ & 75 \\
\hline Dysphagia severity scale ${ }^{a}$ & $0-100$ & $49(34 ; 71)$ & 57 \\
\hline
\end{tabular}

MDADI, the DHI, and the Dysphagia Severity Scale. Confirmatory Maximum Likelihood (ML) factor analyses were performed to determine the number of (homogeneous) (sub)scales in each questionnaire. In addition, by computing Cronbach's $\alpha$ coefficients, the internal-consistency reliability of the MDADI and the DHI was estimated. The associations among the four administered questionnaires plus the FOIS and among the subscales per instrument were determined using nonparametric Spearman's correlation coefficients. (Sub)scales from the MDADI and the DHI that were supposed to measure the same concept were compared to determine construct validity (convergent validity). Finally, criterion validity was determined by computing nonparametric Spearman's correlations between the SWAL-QOL (reference or gold standard) and both the MDADI and the DHI. All statistical analyses were performed using SPSS for Windows 15.0.1 (SPSS Inc., Chicago, IL).

\section{Results}

Table 1 presents the descriptive statistics for all four questionnaires. To examine a possible floor or ceiling effect, the total score of the MDADI, the total score of the 
Table 2 Glossary of psychometric and statistical terms

\begin{tabular}{|c|c|}
\hline Term & Definition \\
\hline Construct validity & $\begin{array}{l}\text { The extent to which a measurement corresponds to theoretical concepts (constructs) concerning the phenomenon under } \\
\text { study [16]. }\end{array}$ \\
\hline Convergent validity & $\begin{array}{l}\text { The degree to which a measure is correlated with other measures to which it is theoretically predicted to correlate. In } \\
\text { contrast, discriminant validity describes the degree to which the measure is not similar to (diverges from) other } \\
\text { measures to which it theoretically should not be similar. Convergent validity and discriminant validity are variants of } \\
\text { construct validity [16]. }\end{array}$ \\
\hline Correlation coefficient & $\begin{array}{l}\text { An index that quantifies the linear relationship between a pair of variables (range }=-1 \text { to } 1 \text { ), with the sign indicating } \\
\text { the direction of the relationship and the numerical magnitude its strength. Values of }-1 \text { or } 1 \text { indicate that the sample } \\
\text { values fall on a straight line, whereas a value of zero indicates the lack of any linear relationship between the two } \\
\text { variables [17]. }\end{array}$ \\
\hline Criterion validity & The extent to which the measurement correlates with an external criterion of the phenomenon under study [16]. \\
\hline Cronbach's $\alpha$ & $\begin{array}{l}\text { The estimate of the correlation between the total score across a series of items from a rating scale and the total score } \\
\text { that would have been obtained had a comparable series of items been employed [16]. Cronbach's } \alpha \text { is an index of } \\
\text { internal consistency of a psychological test ranging from } 0 \text { to } 1 \text {. (Guidelines for interpretation: }<0.60 \text {, unacceptable; } \\
0.60-0.65 \text {, minimally acceptable; } 0.70-0.80 \text {, respectable; } 0.80-0.90 \text {, very good; and }>0.90 \text {, consider shortening the } \\
\text { scale by reducing the number of items [18].) }\end{array}$ \\
\hline Factor analysis & $\begin{array}{l}\text { A set of statistical methods (e.g., maximum likelihood estimation) for analyzing the correlations among several } \\
\text { variables in order to estimate the number of fundamental dimensions that underlie the observed data and to describe } \\
\text { and measure those dimensions [16]. These underlying, unobservable, latent variables are usually known as the } \\
\text { common factors [17]. Using exploratory factor analysis, no hypothesis about the number and kind of common factors } \\
\text { exists prior to analysis. In the case of confirmatory factor analysis, the number of common factors has been } \\
\text { predetermined. }\end{array}$ \\
\hline Floor or ceiling effect & The number of respondents who achieved the lowest or highest possible score $[10,11]$. \\
\hline Goodness of fit & $\begin{array}{l}\text { The degree of agreement between an empirically observed distribution and a mathematical or theoretical distribution } \\
\text { [16]. }\end{array}$ \\
\hline Internal consistency & The extent to which items in a (sub)scale are intercorrelated, thus measuring the same construct [10]. \\
\hline Intraclass correlation & $\begin{array}{l}\text { The proportion of variance of an observation due to between-subject variability in the "true" scores of a measuring } \\
\text { instrument [17]. }\end{array}$ \\
\hline Test-retest reliability & $\begin{array}{l}\text { An index of score consistency over a brief period of time (typically several weeks), usually the correlation coefficient } \\
\text { determined between administration of the test twice with a certain amount of time between administrations [17]. }\end{array}$ \\
\hline
\end{tabular}

DHI, and the Dysphagia Severity Scale have been visualized by means of histograms (Fig. 1a-c). These figures objectify the number of respondents who obtained the lowest or highest possible scores. As less than $15 \%$ of the respondents got the lowest or highest possible score, no floor or ceiling effect was considered to be present $[10,11]$.

To assess test-retest reliability, intraclass correlation coefficients (two-way random effects model, ICC) have been determined between repeated measurements on the total scores of the MDADI and the DHI and on the Dysphagia Severity Scale. The ICCs were 0.96, 0.94, and 0.87, respectively. A positive rating for reliability can be given only when the ICC is at least 0.70 in a sample size of at least 50 patients [10]. Because of missing values, the actual sample sizes used for ICC computation were 64 (MDADI), 35 (DHI), and 49 (Dysphagia Severity Scale). The reliability of the DHI could not be determined appropriately as a consequence of too little data. Both of the other instruments are considered to have good test-retest reliability.

Internal consistency is an important measurement property for questionnaires. It describes the extent to which items in a questionnaire (sub)scale are correlated and thus measure the same concept. For an existing theoretical model or in case the factor structure had been determined previously, confirmatory factor analysis should be applied in order to determine the number of (homogeneous) (sub)scales. To that end, a confirmatory Maximum Likelihood (ML) factor analysis has been performed using all items of the MDADI to test whether three factors could be distinguished (namely, the three subscales). However, this three-factor model was rejected (goodness-of-fit test, $P<0.000)$. A four-factor model, referring to the global assessment as a possible fourth factor, was rejected as well $(P=0.003)$. A confirmatory ML factor analysis using all items of the DHI and a three-factor model also called for rejection of the possibility of three underlying constructs or subscales (goodness-of-fit test, $P<0.000$ ).

Still, as the subject population was rather limited, further analysis was performed to gather more information about the questionnaires' psychometric properties. Cronbach's $\alpha$ was determined because it is considered an adequate measure of internal-consistency reliability. A low Cronbach's $\alpha(\alpha \leq 0.70)$ suggests a lack of correlation [9], whereas a high Cronbach's $\alpha(\alpha>0.90)$ indicates 

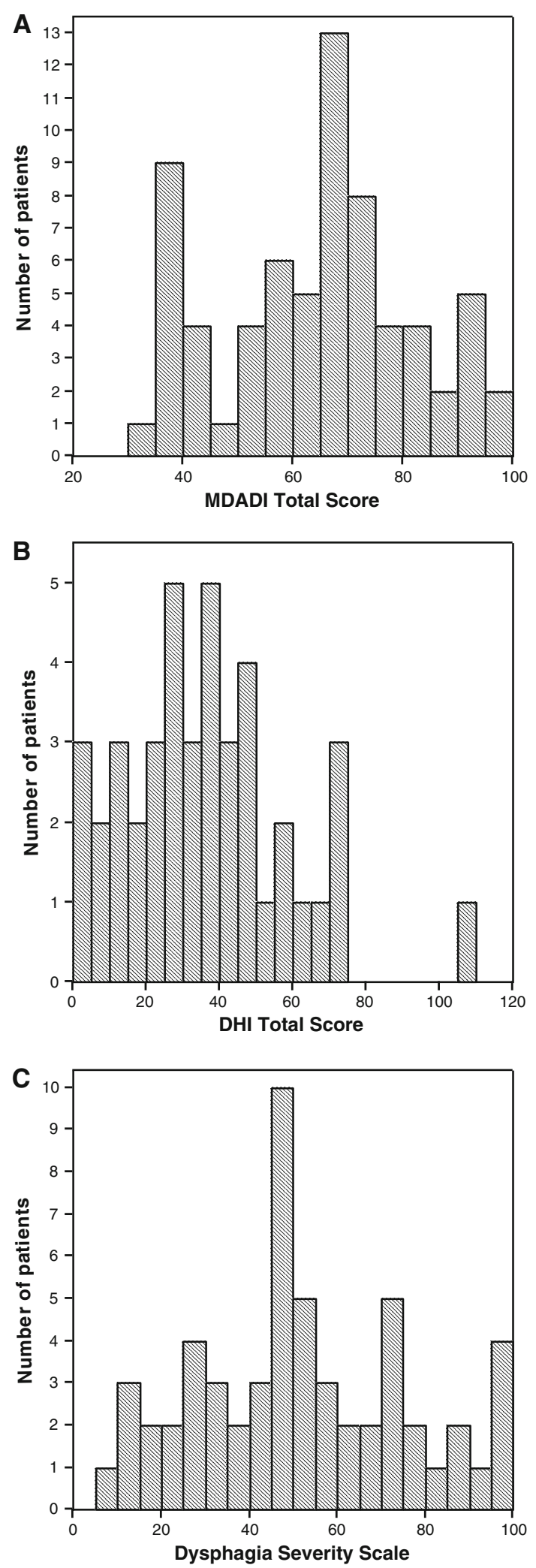

redundancy of one or more items [9, 12]. Cronbach's $\alpha$ was calculated separately for each (sub)scale of the MDADI and the DHI (Table 3). All Cronbach's $\alpha$ values lie between 0.76 and 0.94 , thus indicating good internal consistency,
4 Fig. 1 a Data distribution on the MDADI. The number of patients is displayed as a function of the Total Score on the MDADI. The area under the curve equals the total number of patients. b Data distribution on the DHI. The number of patients is displayed as a function of the Total Score on the DHI. The area under the curve equals the total number of patients. c Data distribution on the Dysphagia Severity Scale. The number of patients is displayed as a function of the score on the Dysphagia Severity Scale. The area under the curve equals the total number of patients

Table 3 Cronbach's $\alpha$ per (sub)scale of the MD Anderson Dysphagia Inventory (MDADI) and the Deglutition Handicap Index (DHI)

\begin{tabular}{ll}
\hline Quality-of-life scale & Cronbach's $\alpha$ \\
\hline MDADI & \\
Total score & 0.94 \\
Global assessment & n.a. \\
Emotional subscore & 0.86 \\
Functional subscore & 0.82 \\
Physical subscore & 0.87 \\
DHI & \\
Total score & 0.93 \\
Emotional subscore & 0.94 \\
Functional subscore & 0.84 \\
Physical subscore & 0.76
\end{tabular}

although some redundancy may be present. Considering the outcome of the factor analyses-no obvious homogeneous (sub)scales detected and adequate Cronbach's $\alpha$ values found per (sub)scale-the internal consistency of both questionnaires seems to remain unclear [10].

The associations among the four patient-administered questionnaires plus the FOIS and among the subscales per instrument were determined by nonparametric Spearman's correlation coefficients as well (Tables 4, 5). For the correlation coefficients $(R)$, a minimum value for a strong correlation was set at 0.7 [13-15]. Correlation coefficients between 0.3 and 0.7 were considered a substantial correlation, and $R$ values less than 0.3 were considered a weak correlation. Negative correlations are expected because all questionnaires except the DHI associate lower scores with more severely impaired quality of life or restricted functional oral intake. Correlations between the quality-of-life instruments and the functional feeding status proved low $(-0.013 \leq R \leq 0.53)$. Construct validity could be determined by comparing the (sub)scales from the MDADI and the DHI that were supposed to measure the same concept. Associations between similar subscales from both questionnaires as well as both total scores demonstrated whether they defined the same target construct (convergent validity). Correlation coefficients for the emotional, functional, and physical subscales from the MDADI and the DHI were $-0.93,-0.65$, and -0.62 , respectively. The correlations between the Dysphagia Severity Scale and 
Table 4 Associations among the MDADI, the DHI, the Dysphagia Severity Scale, and the FOIS (nonparametric Spearman's correlation coefficients)

\begin{tabular}{|c|c|c|c|c|c|c|c|c|c|c|c|}
\hline & \multicolumn{5}{|c|}{ MDADI } & \multicolumn{4}{|l|}{ DHI } & \multirow{2}{*}{$\begin{array}{l}\text { Dysphagia } \\
\text { Severity } \\
\text { Scale }\end{array}$} & \multirow[t]{2}{*}{ FOIS $^{\mathrm{a}}$} \\
\hline & $\begin{array}{l}\text { Total } \\
\text { score }\end{array}$ & $\begin{array}{l}\text { Global } \\
\text { assessment }\end{array}$ & $\begin{array}{l}\text { Emotional } \\
\text { subscore }\end{array}$ & $\begin{array}{l}\text { Functional } \\
\text { subscore }\end{array}$ & $\begin{array}{l}\text { Physical } \\
\text { subscore }\end{array}$ & $\begin{array}{l}\text { Total } \\
\text { score }\end{array}$ & $\begin{array}{l}\text { Emotional } \\
\text { subscore }\end{array}$ & $\begin{array}{l}\text { Functional } \\
\text { subscore }\end{array}$ & $\begin{array}{l}\text { Physical } \\
\text { subscore }\end{array}$ & & \\
\hline \multicolumn{12}{|l|}{ MDADI } \\
\hline Total score & & $\begin{array}{c}0.75 * * \\
(74)\end{array}$ & $\begin{array}{l}0.94 * * \\
(74)\end{array}$ & $\begin{array}{l}0.92 * * \\
(74)\end{array}$ & $\begin{array}{c}0.91 * * \\
(74)\end{array}$ & $\begin{array}{c}-0.87 * * \\
(41)\end{array}$ & $\begin{array}{l}-0.89 * * \\
(44)\end{array}$ & $\begin{array}{l}-0.70^{* *} \\
(43)\end{array}$ & $\begin{array}{c}-0.57 * * \\
(42)\end{array}$ & $\begin{array}{c}0.45^{* *} \\
(57)\end{array}$ & $\begin{array}{c}0.53 * * \\
(74)\end{array}$ \\
\hline $\begin{array}{l}\text { Global } \\
\text { assessment }\end{array}$ & & & $\begin{array}{c}0.68 * * \\
(75)\end{array}$ & $\begin{array}{l}0.72 * * \\
(75)\end{array}$ & $\begin{array}{c}0.66^{* *} \\
(75)\end{array}$ & $\begin{array}{c}-0.72 * * \\
(42)\end{array}$ & $\begin{array}{l}-0.65 * * \\
(46)\end{array}$ & $\begin{array}{l}-0.64 * * \\
(44)\end{array}$ & $\begin{array}{c}-0.65^{* *} \\
(44)\end{array}$ & $\begin{array}{c}0.57 * * \\
(57)\end{array}$ & $\begin{array}{c}0.44 * * \\
(76)\end{array}$ \\
\hline $\begin{array}{l}\text { Emotional } \\
\text { subscore }\end{array}$ & & & & $\begin{array}{l}0.81^{* *} \\
(74)\end{array}$ & $\begin{array}{l}0.82 * * \\
(74)\end{array}$ & $\begin{array}{c}-0.85^{* *} \\
(41)\end{array}$ & $\begin{array}{c}-0.93 * * \\
(45)\end{array}$ & $\begin{array}{c}-0.63 * * \\
(43)\end{array}$ & $\begin{array}{c}-0.52 * * \\
(43)\end{array}$ & $\begin{array}{l}0.43^{* *} \\
\quad(57)\end{array}$ & $\begin{array}{c}0.46 * * \\
(75)\end{array}$ \\
\hline $\begin{array}{l}\text { Functional } \\
\text { subscore }\end{array}$ & & & & & $\begin{array}{l}0.77 * * \\
\quad(75)\end{array}$ & $\begin{array}{c}-0.82 * * \\
(41)\end{array}$ & $\begin{array}{c}-0.86^{* * *} \\
(45)\end{array}$ & $\begin{array}{l}-0.65 * * \\
(44)\end{array}$ & $\begin{array}{c}-0.54 * * \\
(43)\end{array}$ & $\begin{array}{l}0.34 * * \\
(57)\end{array}$ & $\begin{array}{c}0.53 * * \\
(75)\end{array}$ \\
\hline $\begin{array}{l}\text { Physical } \\
\text { subscore }\end{array}$ & & & & & & $\begin{array}{c}-0.82^{* *} \\
(41)\end{array}$ & $\begin{array}{l}-0.75^{* *} \\
(45)\end{array}$ & $\begin{array}{l}-0.78^{* *} \\
(44)\end{array}$ & $\begin{array}{c}-0.62^{* *} \\
(43)\end{array}$ & $\begin{array}{c}0.44 * * \\
(57)\end{array}$ & $\begin{array}{c}0.45^{* *} \\
(75)\end{array}$ \\
\hline \multicolumn{12}{|l|}{ DHI } \\
\hline Total score & & & & & & & $\begin{array}{l}0.89 * * \\
(42)\end{array}$ & $\begin{array}{l}0.84 * * \\
(42)\end{array}$ & $\begin{array}{l}0.78^{* *} \\
\quad(42)\end{array}$ & $\begin{array}{c}-0.52 * * \\
(30)\end{array}$ & $\begin{array}{l}-0.41 * * \\
(42)\end{array}$ \\
\hline $\begin{array}{l}\text { Emotional } \\
\text { subscore }\end{array}$ & & & & & & & & $\begin{array}{c}0.60 * * \\
(44)\end{array}$ & $\begin{array}{c}0.54 * * \\
(44)\end{array}$ & $\begin{array}{c}-0.43^{*} \\
(31)\end{array}$ & $\begin{array}{r}-0.13 \\
(44)\end{array}$ \\
\hline $\begin{array}{l}\text { Functional } \\
\text { subscore }\end{array}$ & & & & & & & & & $\begin{array}{c}0.66^{* *} \\
(42)\end{array}$ & $\begin{array}{l}-0.50 * * \\
(31)\end{array}$ & $\begin{array}{c}-0.36^{*} \\
(44)\end{array}$ \\
\hline $\begin{array}{l}\text { Physical } \\
\text { subscore }\end{array}$ & & & & & & & & & & $\begin{array}{c}-0.45^{* *} \\
(32)\end{array}$ & $\begin{array}{l}-0.40^{* *} \\
(46)\end{array}$ \\
\hline $\begin{array}{l}\text { Dysphagia } \\
\text { Severity Scale }\end{array}$ & & & & & & & & & & & $\begin{array}{c}0.38 * * \\
(57)\end{array}$ \\
\hline FOIS & & & & & & & & & & & \\
\hline
\end{tabular}

* Correlation is significant at the 0.01 level (2-tailed)

** Correlation is significant at the 0.05 level (2-tailed)

${ }^{a}$ Lower scores indicate more severely impaired oral intake

both total scores from the MDADI and the DHI were rather low (0.45 and -0.52 , respectively), whereas the correlation between both total scores of the MDADI and the DHI was strong $(R=-0.87)$. The mean correlation coefficients between the subscales of the MDADI and between the subscales of the DHI were $0.80(0.66 \leq R \leq 0.82)$ and $0.60(0.54 \leq R \leq 0.66)$, respectively.

When considering the SWAL-QOL as the reference standard or gold standard, the extent to which the MDADI and the DHI agreed or correlated with the SWAL-QOL could be defined as the questionnaires' criterion validity. Table 5 presents the associations among the SWAL-QOL versus the MDADI, the DHI, the Dysphagia Severity Index, and the FOIS (nonparametric Spearman's correlation coefficients). The mean correlation coefficients for the subscales from the SWAL-QOL versus the total score of the MDADI, the total score of the DHI, and the Dysphagia Severity Scale were $0.67 \quad(0.39 \leq R \leq 0.86), \quad-0.61$ $(-0.38 \leq R \leq-0.80)$, and $0.36 \quad(0.30 \leq R \leq 0.73)$, respectively. Next, based on the authors' clinical experience, subscales that were considered to be of lesser importance to oropharyngeal dysphagia were excluded by mutual consensus. Thus, when excluding the subscales Fear, Sleep, Fatigue, and Communication, the mean correlation coefficients as determined for this restricted group of subscales were $0.76 \quad(0.62 \leq R \leq 0.86), \quad-0.71 \quad(-0.60 \leq R \leq$ $-0.80)$, and $0.42(0.31 \leq R \leq 0.73)$, respectively. According to Terwee et al. [10], the correlation with the reference standard needs to be at least 0.70 . Only after having excluded the less relevant subscales of the SWAL-QOL did both the MDADI and the DHI show satisfactory associations with the reference standard.

\section{Discussion}

In this study, the psychometric characteristics for the MDADI and the DHI have been determined. The Dysphagia Severity Scale was introduced to reveal any advantages or disadvantages of using elaborate questionnaires compared to using a simple visual analog scale, while the SWAL-QOL was considered the reference or 
Table 5 Associations among the SWAL-QOL versus the MDADI, the DHI, the Dysphagia Severity Scale, and the FOIS (nonparametric Spearman's correlation coefficients)

\begin{tabular}{|c|c|c|c|c|c|c|c|c|c|c|c|}
\hline \multirow[t]{2}{*}{ SWAL-QOL } & \multicolumn{5}{|l|}{ MDADI } & \multicolumn{4}{|l|}{ DHI } & \multirow{2}{*}{$\begin{array}{l}\text { Dysphagia } \\
\text { Severity } \\
\text { Scale }\end{array}$} & \multirow[t]{2}{*}{ FOIS $^{\mathrm{a}}$} \\
\hline & $\begin{array}{l}\text { Total } \\
\text { score }\end{array}$ & $\begin{array}{l}\text { Global } \\
\text { assessment }\end{array}$ & $\begin{array}{l}\text { Emotional } \\
\text { subscore }\end{array}$ & $\begin{array}{l}\text { Functional } \\
\text { subscore }\end{array}$ & $\begin{array}{l}\text { Physical } \\
\text { subscore }\end{array}$ & $\begin{array}{l}\text { Total } \\
\text { score }\end{array}$ & $\begin{array}{l}\text { Emotional } \\
\text { subscore }\end{array}$ & $\begin{array}{l}\text { Functional } \\
\text { subscore }\end{array}$ & $\begin{array}{l}\text { Physical } \\
\text { subscore }\end{array}$ & & \\
\hline Burden & $\begin{array}{c}0.84 * * \\
(71)\end{array}$ & $\begin{array}{c}0.69 * * \\
(73)\end{array}$ & $\begin{array}{c}0.79 * * \\
(72)\end{array}$ & $\begin{array}{c}0.79 * * \\
(72)\end{array}$ & $\begin{array}{c}0.78 * * \\
\quad(72)\end{array}$ & $\begin{array}{c}-0.68 * * \\
(39)\end{array}$ & $\begin{array}{c}-0.77 * * \\
(43)\end{array}$ & $\begin{array}{c}-0.54 * * \\
(41)\end{array}$ & $\begin{array}{c}-0.46^{* * *} \\
(41)\end{array}$ & $\begin{array}{c}0.54 * * \\
(55)\end{array}$ & $\begin{array}{c}0.50 * * \\
(73)\end{array}$ \\
\hline Food selection & $\begin{array}{c}0.77 * * \\
(69)\end{array}$ & $\begin{array}{c}0.67 * * \\
(71)\end{array}$ & $\begin{array}{c}0.68 * * \\
(70)\end{array}$ & $\begin{array}{c}0.80 * * \\
(70)\end{array}$ & $\begin{array}{c}0.78^{* * *} \\
(70)\end{array}$ & $\begin{array}{c}-0.69 * * \\
(38)\end{array}$ & $\begin{array}{c}-0.68 * * \\
(42)\end{array}$ & $\begin{array}{c}-0.69 * * \\
(40)\end{array}$ & $\begin{array}{c}-0.51 * * \\
(40)\end{array}$ & $\begin{array}{c}0.42 * * \\
(54)\end{array}$ & $\begin{array}{c}0.40 * * \\
(71)\end{array}$ \\
\hline Eating duration & $\begin{array}{c}0.70 * * \\
(69)\end{array}$ & $\begin{array}{c}0.57 * * \\
(71)\end{array}$ & $\begin{array}{c}0.63 * * \\
(70)\end{array}$ & $\begin{array}{c}0.66^{* * *} \\
(70)\end{array}$ & $\begin{array}{c}0.72 * * \\
(70)\end{array}$ & $\begin{array}{c}-0.70 * * \\
(39)\end{array}$ & $\begin{array}{c}-0.63 * * \\
(43)\end{array}$ & $\begin{array}{c}-0.69^{* *} \\
(41)\end{array}$ & $\begin{array}{c}-0.40^{*} \\
(41)\end{array}$ & $\begin{array}{c}0.38 * * \\
(55)\end{array}$ & $\begin{array}{c}0.41 * * \\
(71)\end{array}$ \\
\hline Eating desire & $\begin{array}{c}0.71 * * \\
(70)\end{array}$ & $\begin{array}{c}0.56^{* *} \\
(72)\end{array}$ & $\begin{array}{c}0.66^{* *} \\
(71)\end{array}$ & $\begin{array}{c}0.68 * * \\
(71)\end{array}$ & $\begin{array}{c}0.73 * * \\
(71)\end{array}$ & $\begin{array}{c}-0.70 * * \\
(39)\end{array}$ & $\begin{array}{c}-0.70 * * \\
(43)\end{array}$ & $\begin{array}{c}-0.64 * * \\
(41)\end{array}$ & $\begin{array}{c}-0.31^{*} \\
(41)\end{array}$ & $0.32 *(55)$ & $\begin{array}{c}0.38 * * \\
(72)\end{array}$ \\
\hline Fear & $\begin{array}{c}0.57 * * \\
(69)\end{array}$ & $\begin{array}{c}0.58^{* * *} \\
(71)\end{array}$ & $\begin{array}{c}0.52 * * \\
(70)\end{array}$ & $\begin{array}{c}0.49 * * \\
(70)\end{array}$ & $\begin{array}{c}0.59 * * \\
(70)\end{array}$ & $\begin{array}{c}-0.38^{*} \\
(37)\end{array}$ & $\begin{array}{c}-0.42 * * \\
(41)\end{array}$ & $\begin{array}{c}-0.32 * \\
(39)\end{array}$ & $\begin{array}{c}-0.30 \\
(39)\end{array}$ & $0.34 *(53)$ & $\begin{array}{c}0.31 * * \\
(71)\end{array}$ \\
\hline Sleep & $\begin{array}{c}0.39 * * \\
(71)\end{array}$ & $\begin{array}{c}0.36^{* * *} \\
(73)\end{array}$ & $\begin{array}{c}0.31 * * \\
(72)\end{array}$ & $\begin{array}{c}0.47 * * \\
(72)\end{array}$ & $\begin{array}{c}0.42 * * \\
(72)\end{array}$ & $\begin{array}{c}-0.47 * * \\
(39)\end{array}$ & $\begin{array}{c}-0.47 * * \\
(43)\end{array}$ & $\begin{array}{c}-0.40 * * \\
(41)\end{array}$ & $\begin{array}{c}-0.35^{*} \\
(41)\end{array}$ & $0.12(55)$ & $\begin{array}{r}0.26^{*} \\
(73)\end{array}$ \\
\hline Fatigue & $\begin{array}{c}0.46^{* *} \\
(71)\end{array}$ & $\begin{array}{c}0.43 * * \\
(73)\end{array}$ & $\begin{array}{c}0.36^{* * *} \\
(72)\end{array}$ & $\begin{array}{c}0.46^{* * *} \\
(72)\end{array}$ & $\begin{array}{c}0.53 * * \\
(72)\end{array}$ & $\begin{array}{c}-0.42 * * \\
(39)\end{array}$ & $\begin{array}{c}-0.30 * \\
(43)\end{array}$ & $\begin{array}{c}-0.58 * * \\
(41)\end{array}$ & $\begin{array}{c}-0.41 * * \\
(41)\end{array}$ & $0.25(55)$ & $\begin{array}{l}0.21 \\
\quad(73)\end{array}$ \\
\hline Communication & $\begin{array}{c}0.63 * * \\
(69)\end{array}$ & $\begin{array}{c}0.63 * * \\
(71)\end{array}$ & $\begin{array}{c}0.52 * * \\
(70)\end{array}$ & $\begin{array}{c}0.61 * * \\
(70)\end{array}$ & $\begin{array}{c}0.61 * * \\
(70)\end{array}$ & $\begin{array}{c}-0.48 * * \\
(37)\end{array}$ & $\begin{array}{c}-0.46^{* *} \\
(41)\end{array}$ & $\begin{array}{c}-0.36^{*} \\
(39)\end{array}$ & $\begin{array}{c}-0.47 * * \\
(39)\end{array}$ & $0.34 *(53)$ & $\begin{array}{c}0.42 * * \\
(71)\end{array}$ \\
\hline Mental health & $\begin{array}{c}0.86^{* *} \\
(69)\end{array}$ & $\begin{array}{c}0.72 * * \\
(71)\end{array}$ & $\begin{array}{c}0.82 * * \\
(70)\end{array}$ & $\begin{array}{c}0.83 * * \\
(70)\end{array}$ & $\begin{array}{c}0.80 * * \\
(70)\end{array}$ & $\begin{array}{c}-0.80 * * \\
(37)\end{array}$ & $\begin{array}{c}-0.85^{* *} \\
(41)\end{array}$ & $\begin{array}{c}-0.63 * * \\
(39)\end{array}$ & $\begin{array}{c}-0.49 * * \\
(39)\end{array}$ & $\begin{array}{c}0.42 * * \\
(53)\end{array}$ & $\begin{array}{c}0.48 * * \\
(71)\end{array}$ \\
\hline $\begin{array}{l}\text { Social } \\
\text { functioning }\end{array}$ & $\begin{array}{c}0.85^{* *} \\
(71)\end{array}$ & $\begin{array}{l}0.73 * * \\
(73)\end{array}$ & $\begin{array}{l}0.76^{* *} \\
(72)\end{array}$ & $\begin{array}{l}0.90^{* *} \\
(72)\end{array}$ & $\begin{array}{l}0.75^{* *} \\
(72)\end{array}$ & $\begin{array}{c}-0.78^{* *} \\
(39)\end{array}$ & $\begin{array}{c}-0.84 * * \\
(43)\end{array}$ & $\begin{array}{c}-0.62 * * \\
(41)\end{array}$ & $\begin{array}{c}-0.49 * * \\
(41)\end{array}$ & $\begin{array}{c}0.43 * * \\
(55)\end{array}$ & $\begin{array}{c}0.61 * * \\
(73)\end{array}$ \\
\hline Symptoms & $\begin{array}{c}0.62 * * \\
(71)\end{array}$ & $\begin{array}{l}0.66^{* *} \\
(73)\end{array}$ & $\begin{array}{l}0.53 * * \\
(72)\end{array}$ & $\begin{array}{l}0.58 * * \\
(72)\end{array}$ & $\begin{array}{l}0.61 * * \\
(72)\end{array}$ & $\begin{array}{c}-0.60 * * \\
(39)\end{array}$ & $\begin{array}{c}-0.54 * * \\
(43)\end{array}$ & $\begin{array}{c}-0.51 * * \\
(41)\end{array}$ & $\begin{array}{c}-0.73 * * \\
(41)\end{array}$ & $\begin{array}{l}0.41 * * \\
(55)\end{array}$ & $\begin{array}{c}0.33^{* *} \\
(73)\end{array}$ \\
\hline
\end{tabular}

gold standard. None of the quality-of-life questionnaires showed any floor or ceiling effect. The test-retest reliability of the MDADI and the Dysphagia Severity Scale proved to be good. However, because too much data were missing for the DHI, its test-retest reliability could not be determined, although the intraclass correlation coefficients were rather high. The internal consistency using Cronbach's $\alpha$ seemed to be good. However, when applying confirmatory factor analysis, the underlying constructs as defined by the subscales per questionnaire could not be distinguished. Probably because of unclear constructs, only the two emotional subscales were strongly correlated, whereas the associations between the other corresponding subscales were just moderate. Overall, the Dysphagia Severity Scale showed rather low correlations with the other three questionnaires. It seemed that a detailed questionnaire could not be replaced by a single one-item scale quantifying the severity of the swallowing disorder. The concepts being measured proved to be different. When considering the criterion validity, the MDADI and the DHI showed satisfactory associations with the SWAL-QOL after having removed its less relevant subscales.
Considering both the MDADI and the DHI, it is concluded that neither of these two questionnaires will generate perfect psychometric data. While striving to use questionnaires with the most optimal properties, the ultimate choice will be made by future researchers themselves. Depending on the purposes of their studies, they may choose the somewhat elaborate SWAL-QOL or one of the other two questionnaires with reasonable (though not perfect) psychometric characteristics. Another solution might be to develop a new quality-of-life questionnaire.

\section{Conclusions}

In conclusion, when assessing the validity and reliability of the Dutch version of the MDADI and the DHI, not all criteria for psychometric properties have been adequately met. In general, the importance of determining these characteristics and of objectifying concepts such as validity and reliability must be stressed when developing a questionnaire. If a questionnaire's quality proves to be poor, the study results cannot be interpreted correctly nor can any 
clinical relevance be determined. Therefore, it is recommended that future outcome studies should use only quality-of-life questionnaires that have sufficiently good psychometric characteristics.

Open Access This article is distributed under the terms of the Creative Commons Attribution Noncommercial License which permits any noncommercial use, distribution, and reproduction in any medium, provided the original author(s) and source are credited.

\section{References}

1. Sherman AC, Simonton S, Camp Adams D, Vural E, Owens B, Hanna E. Assessing quality of life in patients with head and neck cancer. Arch Otolaryngol Head Neck Surg. 2000;126:459-67.

2. García-Peris P, Parón L, Velasco C, de la Cuerda C, Camblor M, Bretón I, Herencia H, Verdaguer J, Navarro C, Clave P. Longterm prevalence of oropharyngeal dysphagia in head and neck cancer patients: Impact on quality of life. Clin Nutr. 2007;26: 710-7.

3. Speyer R, Baijens LW, Heijnen MAM, Zwijnenberg I. The effects of therapy in oropharyngeal dysphagia by speech therapists: a systematic review. Dysphagia. 2010;25(1):40-65.

4. McHorney CA, Robbins J, Lomax K, Rosenbek JC, Chignell K, Kramer AE, Bricker DE. The SWAL-QOL and SWAL-CARE outcomes tool for oropharyngeal dysphagia in adults: III. Documentation of reliability and validity. Dysphagia. 2002;17:97-114.

5. Chen AY, Frankowski R, Bishop-Leone J, Hebert T, Leyk S, Lewin J, Goepfert $\mathrm{H}$. The development and validation of a dysphagia-specific quality-of-life questionnaire for patients with head and neck cancer: the MD Anderson Dysphagia Inventory. Arch Otolaryngol Head Neck Surg. 2001;127:870-6.

6. Woisard V, Andrieux MP, Puech M. Validation of a selfassessment questionnaire for swallowing disorders (Deglutition Handicap Index). Rev Laryngol Otol Rhinol (Bord). 2006;127(5): 315-25.

7. Crary MA, Carnaby Mann GD, Groher ME. Initial psychometric assessment of a functional oral intake scale for dysphagia in stroke patients. Arch Phys Med Rehabil. 2005;86:1516-20.

8. Bogaardt HC, Speyer R, Baijens LW, Fokkens WJ. Cross-cultural adaptation and validation of the Dutch version of SWAL-Qol.
Dysphagia. 2009;24:66-70.

9. Streiner DL, Norman GR. Health measurement scales: a practical guide to their development and use. Oxford: Oxford University Press; 2003.

10. Terwee CB, Bot SDM, de Boer MR, van der Windt DAWM, Knol DL, Dekker J, Bouter LM, de Vet HCW. Quality criteria were proposed for measurement properties of health status questionnaires. J Clin Epidemiol. 2007;60:34-42.

11. McHorney CA, Tarlov AR. Individual-patient monitoring in clinical practice: are available health status surveys adequate? Qual Life Res. 1995;4(4):293-307.

12. Bland JM, Altman DG. Cronbach's alpha. BMJ. 1997;314(7080): 572.

13. McDowell I, Newell C. Measuring health. A guide to rating scales and questionnaires. New York/Oxford: Oxford University Press; 1996.

14. Aday LA. Designing and conducting health surveys. San Francisco: Jossey-Bass Publishers; 1996.

15. DeVellis RF. Scale development. Theory and applications. Thousand Oaks: Sage Publications; 2001.

16. Last JM, editor. A dictionary of epidemiology. Oxford: Oxford University Press; 2001.

17. Everitt BS. Medical statistics from A to Z: a guide for clinicians and medical students. Cambridge: Cambridge University Press; 2006.

18. Everitt BS. The Cambridge dictionary of statistics. Cambridge: Cambridge University Press; 2003.

Renée Speyer MSc, SLP, PhD

Bas J. Heijnen MSc, SLP

Laura W. Baijens MD

Femke H. Vrijenhoef MD

Elsemieke F. Otters MD

Nel Roodenburg SLP

Hans C. Bogaardt MSc, SLP, PhD 